\title{
Mit diesen vier Mitteln bekämpfen wir Diabetes
}

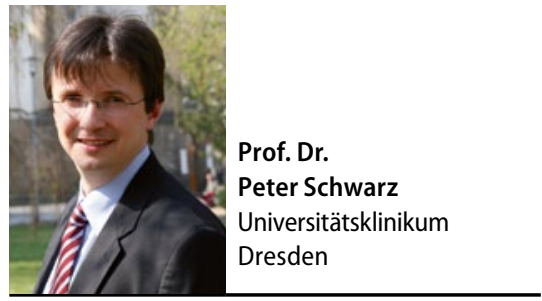

\begin{abstract}
Warum bekommen wir die Diabetes-Epidemie nicht in den Griff, wenn doch jeder weiß, wie man sich gesund ernährt? Offenbar greifen alle Präventionskonzepte zu kurz. Was wir brauchen, ist eine echtes politisches Projekt. Hier sind vier wichtige Anregungen.
\end{abstract}

- Wirksame Präventionsmaßnahmen, um die Entwicklung von Typ-2-Diabetes zu verhindern, stehen seit Jahren zu Verfügung. Eingesetzt werden sie kaum. Das könnte daran liegen, dass ihre Praktikabilität zwar in Studien belegt wurde - dass diese aber vor 20 und 25 Jahren geplant wurden. Damals war das Lebensumfeld hinsichtlich Teilhabe, Ernährung und Bewegung ein völlig anderes als heute. Deshalb muss man auch mit den Ergebnissen dieser Studien kritisch umgehen.

Wir leben heute in einem "Toxic Food Environment“. Besucht man den Supermarkt, sind mehr als 35\% der Produkte nicht nur nicht gesund, sondern sogar gesundheitsschädlich, wenn man sie zu häufig konsumiert. Daneben führt mobile Technologie zu mehr Inaktivität und weniger sozialer Teilhabe.

Ein weiteres Manko: Emotional betonte Werbekampagnen etwa für Fastfood können den Konsumenten viel besser beeinflussen als rationale Aufklärungskampagnen zu Diabetes oder anderen chronischen Erkrankungen. Das führt zu einem „Präventionsparadox“: Jeder weiß, wie er gesund leben könnte ist aber emotional an bestimmte, oft ungesunde Produkte gebunden.

Das Lebensumfeld ist also viel stärker adipogen als früher - und wir brauchen drastischere Maßahmen der Prävention. Unsere Arbeitsgruppe hat nun vier Forderungen formuliert. Gerichtet sind sie an die politisch Verantwortlichen [Diabetes Care. 2016;39(Suppl 2):S121-6].

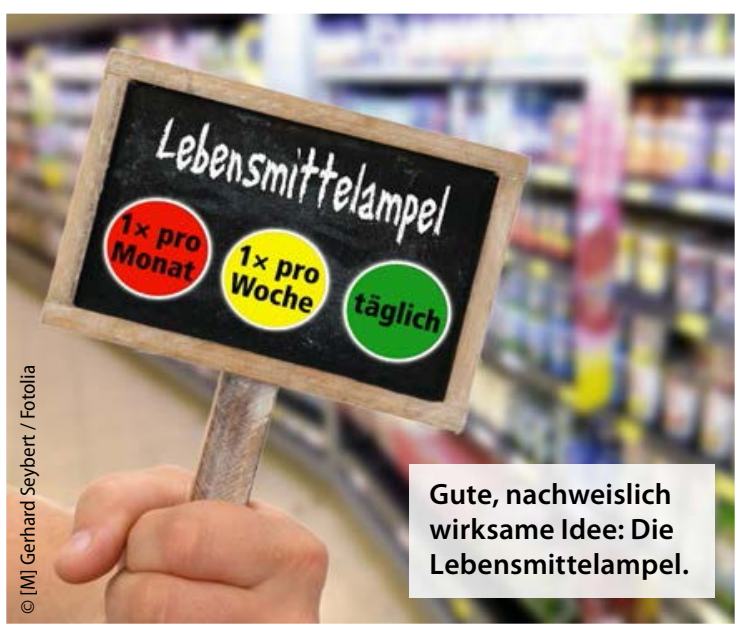

1. Eine Haftung für unerwünschte gesundheitliche Nebenwirkungen von Nahrungsmittelprodukten. Die Nahrungsmittelindustrie würde anfangs zetern, das Haftungsrisiko nach einer gesetzlichen Regelung aber schnell im Produktpreis berücksichtigen. Wir kennen das von der Pharmaindustrie. Die Preise für ungesunde Produkte würden also steigen - ganz wie wir es wollen! Der preissensitive Verbraucher würde diese Produkte seltener kaufen. Der Effekt wäre der gleiche wie der einer Steuer auf ungesunde Produkte.
2. Kennzeichnung der Nahrungsmittel nach einem Ampelsystem. Darüber wird viel diskutiert, weil die bestehende Kennzeichnung nicht verständlich ist. Unser Vorschlag: Grün für den täglichen Verzehr, Gelb für einmal pro Woche, Rot für einmal im Monat. So würde das Verbraucherverhalten direkt positiv beeinflusst. Die Industrie verteufelt eine solche Kennzeichnung - wirksam wäre sie aber.

3. Eine Währung für Gesundheit. Für gesundes Verhalten und den Kauf gesunder Produkte sollte man Gesundheitsmarken erhalten, für die man wiederum andere, aber nur gesunde Produkte kaufen kann. Mit einer solchen Währung könnte man die Liquidität im Gesundheitssektor um bis zu 30\% erhöhen - und gesundes Verhalten doppelt unterstützen.

4. Steuerbefreiung für Präventionsmaßnahmen. Mit Krankheit kann man steuerfrei Geld verdienen, mit Prävention häufig nicht. Eine Steuerbefreiung für nachhaltige Maßnahmen kann dazu führen, dass Krankenkassen, Privatpersonen und Gesellschaften, aber auch Investoren aus der Wirtschaft diesen Bereich für sich entdecken.

- Der Autor leitet die Abteilung Prävention der Medizinischen Klinik III am Universitätsklinikum Carl Gustav Carus, Dresden. 